\title{
Numerical Modelling of Overburden Deformations
}

\author{
J. Barták, M. Hilar, J. Pruška
}

This paper focuses on the application and verification of mathematical models of the effect of supporting measures on the reduction of overburden deformations. The study of the behaviour of the models is divided into three parts: reduction of the tunnelling effects on the Minorit monastery by means of a jet-grouting curtain; the behaviour of the Hvizzdalka backfilled tunnel and a numerical analysis of the supporting measures affecting the tunnel deformations of the Mrázovka tunnel in Prague.

Keywords: numerical modelling, overburden deformations.

\section{The Minorit monastery}

The existence of a settlement above underground structures excavated in poor quality types of ground and at small depths below the surface must be taken into account, especially as regards existing buildings standing within the reach of underground works. The main factors influencing the maximum amount of surface settlement, the shape and extent of the settlement are as follows: the physical - mechanical properties of the rock environment, the tunnelling method, the dimensions of the underground works, the depth of the underground structure below the surface and the stress conditions within the rock mass. Conditions which make excavation dangerous as regards the amount of settlement are cohesive soils (soft and solid consistency), poorly settled soils, incohesive soils supercharged due to a lowered water table, semi-rocks and more deformational rocks. It can be stated that the New Austrian Tunnelling Method (NATM), applied with short advances per cycle and with increased rigidity of the lining, restricts the possible occurrence of inadequate deformations of the massif or of the surface area.

Suitable modifications of NATM or other special tunnelling techniques such as horizontal jet-grouting, peripheral slot or consolidation grouting enable other reductions of surface settlement. Settlement phenomena are generally increased in linear dependence on the growing excavated cross section of the underground structure (especially with increasing dimensions of its width). Major deformations occur if the overburden is shallow $(d \leq w)$. The size of the deformations decreases with increasing depth, and becomes negligible below a certain level. The dimensions of the settlement are, apart from other data, a function of the non-measurable argument $d / w$. In most cases, a state of stress originates in a rock mass after excavation, where the highest values and the deciding importance lie in the vertical stresses. In a number of cases there are stress conditions, where the significant influence comes from residual components of the horizontal stress.

\subsection{The method for securing the foundations of a monastery during excavation of a secondary utility tunnel}

The fifth stage of the secondary utility tunnel structure in Brno passed under Jánská Street, beneath the building of the Minorits monastery. The tunnel with the horseshoe-shaped profile and an area of $10 \mathrm{~m}^{2}$, was situated below the foundation level of the monastery, and the deformation zone of the tunnel collided with the monastery foundation within a length of about $50 \mathrm{~m}$. It was necessary to secure the foundations of the Minorit monastery by underpinning, at present mostly by means of columns created by jet-grouting. Although the interference with the foundation structures of a building is not so drastic when jet-grouting is used, the owners and supervisors of the monastery refused to allow drilling or grouting in direct contact with their buildings. The issue was therefore solved by building a quite sizeable wall formed by columns created by jet-grouting (dia. $0.75 \mathrm{~m}$ per $1.5 \mathrm{~m}$, length $5.5 \mathrm{~m}$ ). The purpose of the wall was to separate the subsoil of the Minorite monastery from settlement caused by the utility tunnel (Fig. 1).

A grout curtain was constructed beyond the building of the monastery (the transverse distance from the foundation structures was about $1.0 \mathrm{~m}$ ). Neither the building nor its

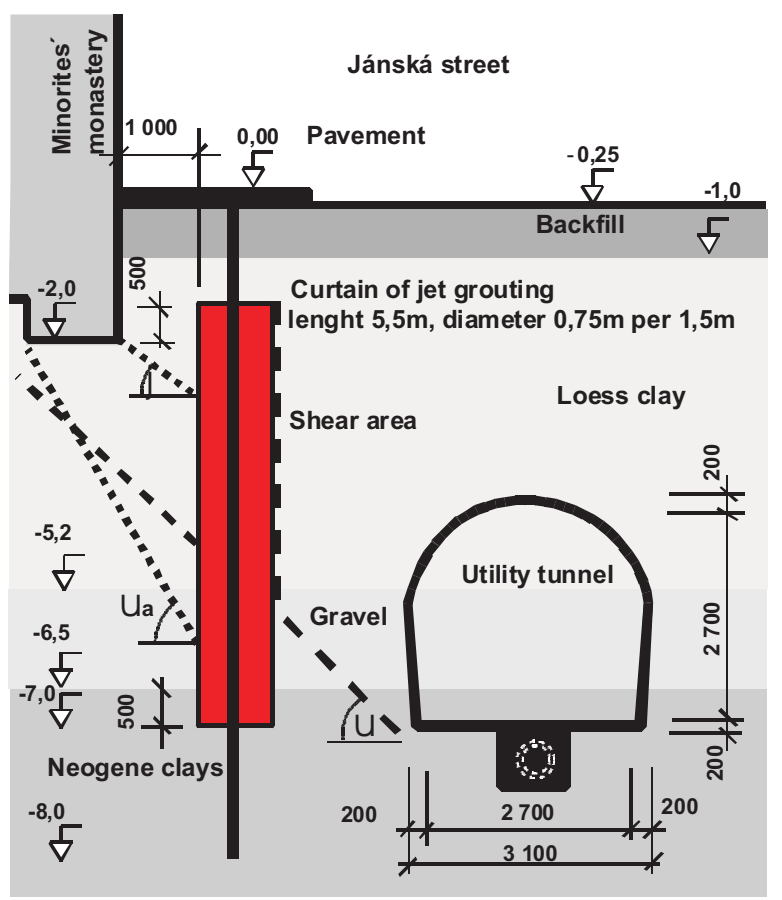

Fig. 1: Cross section $\mathrm{A}_{-} \mathrm{A}^{\prime}$ 
foundation was directly touched by the protective structure. The location of the borehole for jet-grouting inside the zone of the utility services under the sidewalk necessitated the provision of a casing pipe embedded in the bottom of a pre-dug trench, uncovering the utility services. Minimisation of soil loosening in the deformed settlement zone was a prerequisite for the assumed function of the grout curtain.

\subsection{Theoretical solution of the grout curtain function by FEM}

The whole course of the construction of the jet-grouting curtain and of the subsequent utility tunnel excavation was computer simulated, using PLAXIS software. The current version of PLAXIS software enables detailed phasing of the task, which was a prerequisite for modelling of the process of securing the Minorit monastery. An area $21 \mathrm{~m}$ wide down to a depth of $17 \mathrm{~m}$ was modelled for the calculation. The vertical edges of the whole area were fixed against horizontal displacement, and the bottom end was secured against vertical displacement. Horizontal displacement was also prevented along the two vertical edges of the monastery wall. An automatic generator was used to generate the finite element mesh. Fifteen-noded triangular elements, which enabled a sufficiently accurate analysis to be performed, were used for the modelling. We concentrated on the following computation phases:

- Primary state of the stress.

- Excavation of the pit for monastery foundation.

- Loading at the foundation level by the dead weight of the monastery.

- Execution of the jet grouting curtain.

- Setting of the jet grouting curtain.

- Operable load above the future excavated space.

- The tunnel excavation proper.

PLAXIS software operates in such a way that when the primary state of stress is being computed, the finite element mesh remains undeformed. However, the stress value corresponds to the real situation. A partial defect of the model appeared in this phase, which does not however affect the other phases of computation. The defect appeared as result of the relief at foundation level, caused by deactivation of elements in the construction pit. This process manifested itself in an upward deformation of the mesh by $12 \mathrm{~mm}$. This behaviour of the mesh, which does not correspond to the real case, is caused by the elastic behaviour of the mesh elements. As a result of deactivation, the stress under the foundation level was also slightly reduced.

As a result of the activation of a uniform load, vertical deformations of the foundations occurred. The vertical deformations increased by $42 \mathrm{~mm}$, which represents a total settlement of $30 \mathrm{~mm}$. As anticipated, a stress concentration occurred under the foundation level. Horizontal deformations up to $1.6 \mathrm{~mm}$ and vertical deformations up to $1.3 \mathrm{~mm}$ occurred in the area of the diaphragm wall when the jet-grout curtain was set. The increase on that deformations (and the stress) under the load due to the superimposed load on the overburden was $1.3 \mathrm{~mm}$. All deformations of the excavated space occurred in the inward direction: roof - $35 \mathrm{~mm}$; bottom $-50 \mathrm{~mm}$; walls $-6 \mathrm{~mm}$. The deformations of the other parts of the massif were: terrain above the excavation - settlement of 15-20 mm; monastery foundations - settlement of $6.5 \mathrm{~mm}$; maximum horizontal displacement of the diaphragm wall $-3.5 \mathrm{~mm}$.

\subsection{In-situ measurements}

The progress of the monastery foundation settlement was monitored by means of levelling. The final measured values of the foundation settlement in the longitudinal direction fluctuated between $2.1 \mathrm{~mm}$ and $5.9 \mathrm{~mm}$. The settlement value determined by PLAXIS was $6.5 \mathrm{~mm}$. The horizontal displacements of the diaphragm wall were measured by means of inclinometers placed directly in the wall (in two profiles 01 and 02). Through this measurement the horizontal deformation of the measuring sleeve be measured with accuracy greater than $\pm 0.2 \mathrm{~mm}$ per $1 \mathrm{~m}$ of the measuring sleeve length [6]. For the sake of comparison, the measured and computed values are shown in a single diagram (Fig. 2). The individual curves correspond quite well especially in the values of the maximum achieved displacement. The maximum horizontal displacement determined by measurement was $2.65 \mathrm{~mm}$, and by modelling $3.5 \mathrm{~mm}$, which represents a total difference of $0.85 \mathrm{~mm}$. The deviation of the computed curve from the measured values is shown at the foot of the diagram. This deviation is probably related to the manner of taking the measures, which assumed a non-slide bearing of the inclinometer footing.

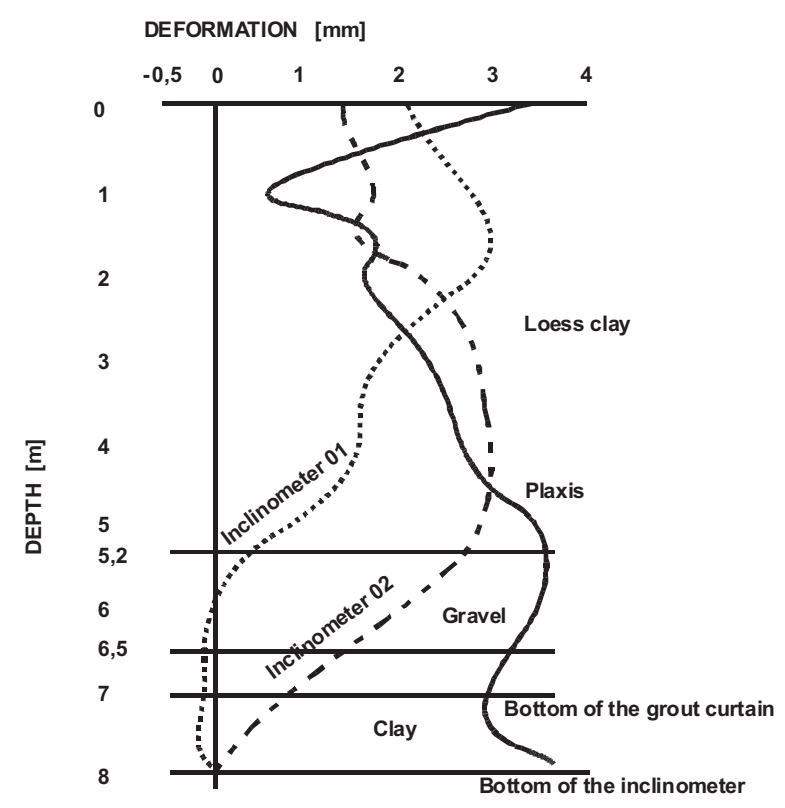

Fig. 2: Horizontal deformation of grout curtain

\subsection{Conclusion}

The in-situ measured horizontal deformations of the protective wall $(3 \mathrm{~mm})$ are of the same order as the deformations determined by PLAXIS $(3.5 \mathrm{~mm})$. Their effect on the horizontal settlement of the monastery foundation and on the origin of defects in the building can be classified as negligible. This fact was confirmed by levelling, which determined the maximum value of of $5.9 \mathrm{~mm}$ for the foundation settlement of the monastery. This value is consistent with the settlement value determined by PLAXIS modelling. 


\section{Hvížd'alka backfiled tunnel}

The Hvíždalka open limestone quarry is situated in the valley of the Radotín brook, and forms rather unsightly pit in a beautiful landscape. This is why it was decided to restore and afforest the site, using filling material, and providing a bottom to the open cast mine to make it accessible by a backfilled tunnel. Settlement of this tunnel structure, deformation of the lining and contact stress are measured all the time during the backfilling [1]. The behaviour of the Hvížd'alka backfilled tunnel was modeled using commercial PLAXIS software. The observation of the deformations for the Hvíždalka tunnel enabled the computer procedure to be validated.

\subsection{Description of the model}

Numerical analysis was carried out by means of the PLAXIS program system. An automatic generator was used to create the finite element mesh. For modelling we used quadratic six-node triangular elements, which enable a sufficiently accurate analysis to be performed. The modelled area covers an area about $60 \mathrm{~m}$ width and $50 \mathrm{~m}$ in height (Fig. 3). The tunnel tube has a cross-section area of $30 \mathrm{~m}^{2}$ (Fig. 4). The length depends on the quarry output and will be from $224 \mathrm{~m}$ to $450 \mathrm{~m}$. The tunnel is backfilled with filling material (stripping soils, aggregates from cement material extraction). The lateral backfill causes lateral movements and thus the computational model counts with an interaction between the lining and the soil. The rock mass behaviour was approximated by means of the Mohr-Coulomb model. The input parameters of the subsoil were determined on the basis of the results of the engineering-geological investigations. The parameters of the lining and filling material were determined in compliance with the detailed design. For the computational models, the following input data were considered:

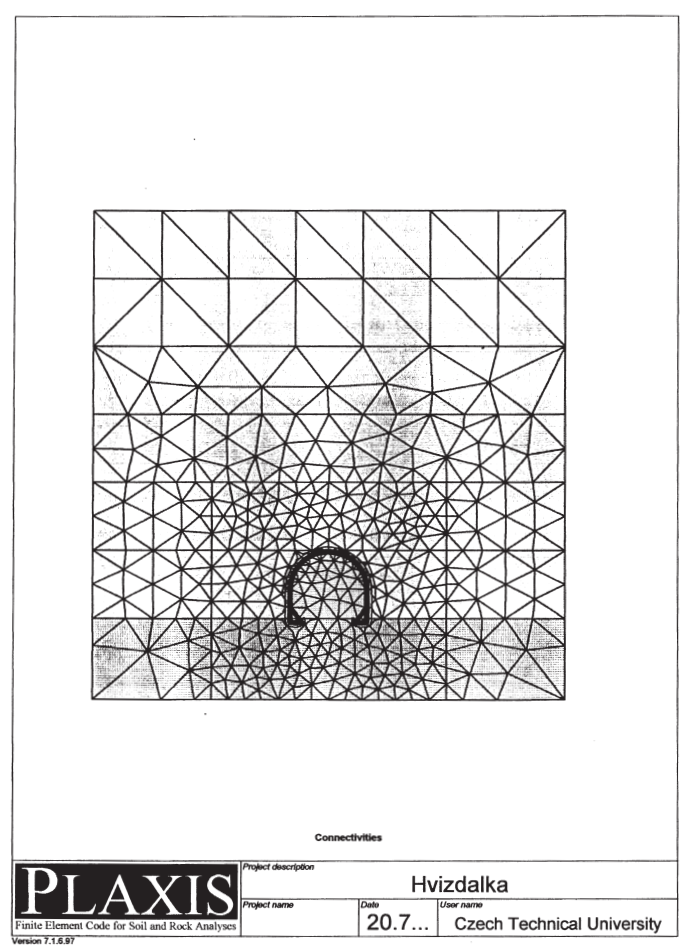

Fig. 3: Numerical model of the Hvížd'alka tunnel
- backfill: $E=20 \mathrm{MPa} ; \nu=0.3 ; \gamma=23 \mathrm{kN} / \mathrm{m}^{3} ; \varphi=20^{\circ}$; $c=29 \mathrm{kPa}$

- subsoil: $E=2000 \mathrm{MPa} ; v=0.15 ; \gamma=25 \mathrm{kN} / \mathrm{m}^{3}$

- lining: $E=30000 \mathrm{MPa} ; v=0.14 ; d=0.85 \mathrm{~m}$, $w=21.25 \mathrm{kN} / \mathrm{m} / \mathrm{m}^{\prime}$.

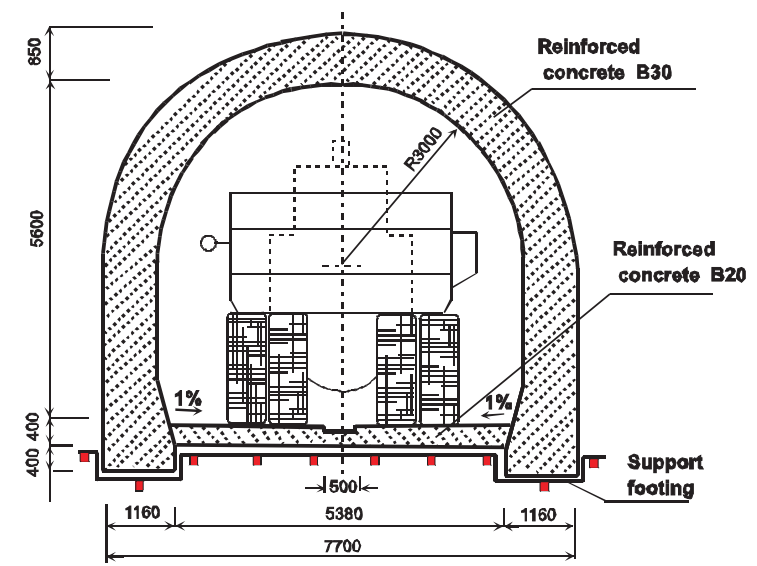

Fig. 4: Cross-section of the Hvíždalka tunnel

\subsection{Computation phases}

The static analysis in calculating the sectional forces and deformations is based on the following computation phases concept:

- Primary state of stress in the subsoil.

- Execution of the lining.

- Execution of compacted backfill.

- Placement of the last layer of backfill.

- Loading of backfill above the tunnel roof.

\subsection{Conclusion}

The numerical model, which was implemented with PLAXIS software, corresponds a adequately with the in-situ measurements. It should be pointed out that during construction the filling material close to the lining was strengthened by cement binder.

\section{Mrázovka tunnel in Prague}

The north-western sector of the City Circular Road in Prague contains three major road tunnels of large cross section area. While the Strahov tunnel is already open for traffic, the Mrázovka tunnel is still under construction (driving of the western tunnel tube (WTT) started at the beginning of 1999) and the Blanka tunnel is still in the planning phase. The very difficult Prague Ordovician geological conditions make it necessary to apply NATM with horizontal sequencing of the excavation. Stabilization of the deformations was always achieved only after closure of the whole primary lining, but the following supporting technical measures were performed: anchoring, widening of the top heading legs, micropile support under the top heading legs, reinforcing grouting performed in advance from the exploratory gallery, and closing the top heading by a temporary invert. Due to increased deformations occurring at the excavation with a horizontally 
divided face, a vertical pattern of the sequence was used in the further course of excavating the Mrázovka tunnel.

\subsection{Description of the starting model}

The numerical analysis was carried out by means of the PLAXIS program system. 3D behaviour of the excavation face area, and correct description of the influence on the deformations and the state of the massif, were simulated by means of the frequently used procedure of loading the excavation and lining using the so-called $\beta$-method. The geometry of the starting model of the profile at km 5.160 WTT covers an area of about $200 \mathrm{~m}$ wide and $110 \mathrm{~m}$ high. The modelled area is divided into eight basic sub-areas according to the types of rock encountered (Fig. 5). The rock mass behaviour was approximated by means of the Mohr-Coulomb model. The input parameters of the rock mass were determined on the basis of the engineering-geological investigation results [3]. The modulus of deformation of the tectonic zone was determined according to the results of plate bearing tests. A comparison of theoretically determined deformations with the values obtained by monitoring [5] was used verifying the applicability of the mathematical model. A parametric study was developed, which proved that the concurrence of unfavourable values of the rock mass (within the limits determined by the geotechnical investigation) could be the cause of the increase in real deformation above the values computed by means of the mathematical model.

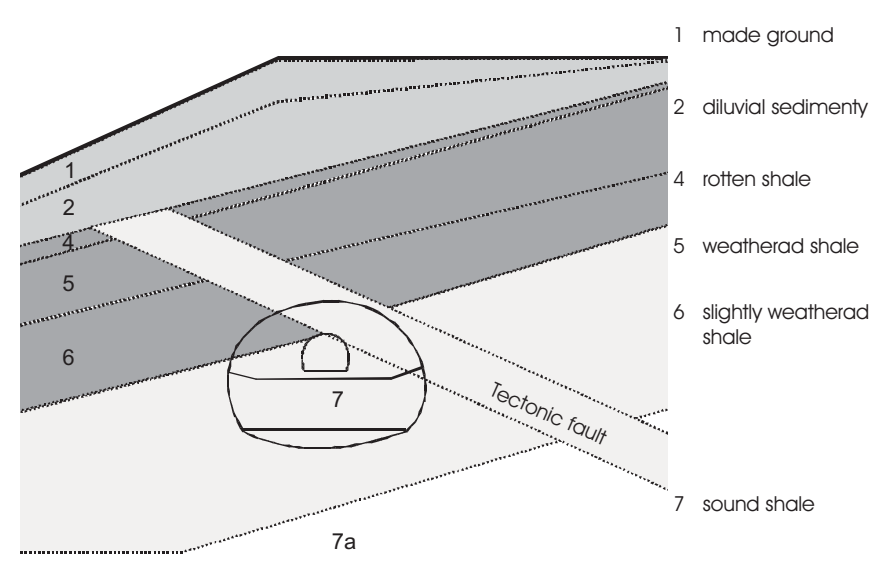

Fig. 5: Division of the model

\subsection{Results of modelling of the supporting measures}

\subsubsection{Reinforcing grouting}

Grouting boreholes were drilled from one centre on the centre line of the exploratory gallery, at an angle of 30 to $36^{\circ}$ from the longitudinal axis, in a radial array, creating a fan shape (Fig. 6). A cementation mixtures stabilized by bentonite was used as the grouting mix. Evaluation of the effect of the grouting on improving the mechanical properties of the rock mass was performed by means of pressiometry [4]. It followed from the results of the series of pressiometric tests that:

- The modulus of deformation of the grouted rock increased by an average of $64 \%$.
- The cohesion of the grouted rock increased by an average of $49 \%$.

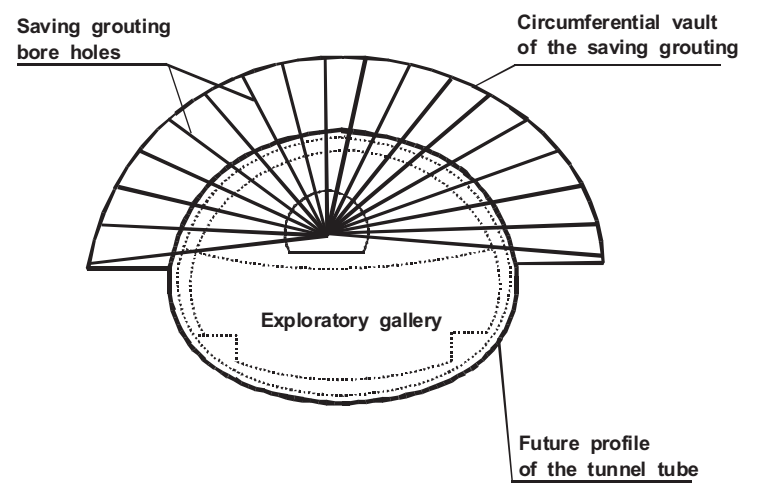

Fig. 6: Scheme of the execution of the saving grouting

The outputs determined by the modelling show that the grouting that was performed causes a reduction of $12 \mathrm{~mm}$ (about $10 \%$ ) in the deformations. One of the reasons for this is probably the insufficiently large area of the grouted rock (an area up to a distance of $4 \mathrm{~m}$ from the tunnel tube was injected). Another reason for the lower effectiveness is the influence of the significant tectonic fault existing in the monitored profile. Regarding the models of the reinforcing grouting, it should be noted that planar models do not take into consideration the favourable spatial effect of this measure, which may not be negligible.

\subsubsection{Rockbolt support}

SN-type rock bolts made from deformed reinforcing bars, steel grade $10425,32 \mathrm{~mm}$ in diameter, were used at the profile. The bar was inserted into boreholes $48 \mathrm{~mm}$ in diameter, filled with cementatious mortar. The bolts were $4 \mathrm{~m}$ long. The rock bolts were installed along the tunnel perimeter at $2 \mathrm{~m}$ spacing, and their spacing in the longitudinal direction was also $2 \mathrm{~m}$. Of the 4 types of models of anchoring that were used (fixation along the overall length of the bolt, fixation at the root and head of the bolt, approximation by force effects, improvement of the shear strength on the grouted area of the massif) the most suitable is the model of rockbolts fixed in the massif at the root and in the lining at the head. The results of complex modelling of the anchoring show the fundamental (and known) influence of the length of the time lag between installation of the rockbolts and installation of the primary lining. Rock bolts installed simultaneously with the lining improved the final magnitude of the deformations by up to $90 \mathrm{~mm}(45 \%)$, but when there is a time lag between installation, the maximum resulting improvement is $18 \mathrm{~mm} \mathrm{(9 \% ).}$

\subsubsection{The micropile support}

Pipes $70 \mathrm{~mm}$ in diameter with a wall thickness of $7 \mathrm{~mm}$ were used for the top heading support. The length of the right-hand micropile was $12 \mathrm{~m}$ (root length $8 \mathrm{~m}$ ), and the left-hand micropile was $9 \mathrm{~m}$ in length (root length $6 \mathrm{~m}$ ). The micropiles were installed under the widened legs after the lining concrete of the top heading had set. The influence of the time lag between the installation of the micropiles and the application of shotcrete on the top heading lining is shown in 
the results of the complex modelling. The high concentration of stresses in the concrete of the vault leg at the contact with the micropiles played the main role in the realization. These stresses lead to subsequent penetration of the micropiles through the lining.

\subsubsection{Temporary invert of the top heading}

Temporary closing of the top heading by invert is a measure which can be effectively applied to influence the deformations of the tunnel lining when there is horizontal sequencing of the tunnel face. Howerver, this measure adversely affects the fluent and economic progress of the works. The computed values of the internal stresses show that their magnitude decreases significantly (by about 2/3) with a growing time lag in realization. Nevertheless, the subsequently performed joint at the foot of the top heading lining should be able to transmit all three types of internal forces.

\subsubsection{Vertical sequencing of the face}

The transition from the horizontal to the vertical sequencing of the face enables a notable reduction in the magnitude of the deformations (Fig. 7). The vertical pattern of the sequencing used in the further course of the Mrázovka tunnel excavation was used for this modelling. The reinforcement of the lining of the sidewall drifts was taken over from the performance documentation (sprayed B25concrete $250 \mathrm{~mm}$ thick, BRETEX $1 * 25$ and $2 * 16 \mathrm{~mm}$ ribs). It follows from the model results that the final deformation will amount to $114 \mathrm{~mm}$ if the full profile excavation of the sidewall drifts is applied. If the drifts are divided into two branches, the final deformation will amount to $134 \mathrm{~mm}$.
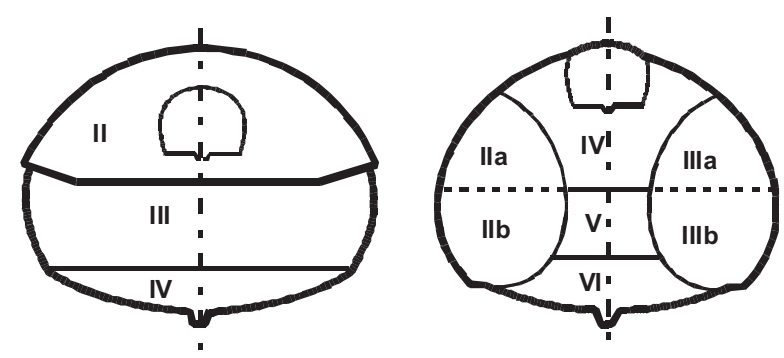

Fig. 7: Scheme of the sectioning of the faces

\subsection{Conclusion}

The analysis was carried out by means of modelling using the Finite Element Method. The design and monitored parameters at the profile km 5.160 WTT Mrázovka tunnel were used as source data for the analysis. The comparative absolute values are related to the model with the exploratory gallery (Tab. 1).

The most clearly effective measure, both theoretically and, at other profiles, also practically, proved to be the transition from the horizontal to the vertical sectioning of the tunnel face [7]. In combination with reasonably promptly installed rockbolt support, we can expect a reduction in the deformations within the range of 50 to $70 \%$. It should be stated that
Table 1: Influence of supporting measures on resulting deformations

\begin{tabular}{|c|c|c|c|c|}
\hline $\begin{array}{l}\text { Model } \\
\text { title }\end{array}$ & $\begin{array}{c}\text { Surface } \\
{[\mathrm{mm}]}\end{array}$ & $\begin{array}{c}\text { Tunnel } \\
\text { roof } \\
{[\mathrm{mm}]}\end{array}$ & $\begin{array}{l}\text { Reduction } \\
\text { at the } \\
\text { surface } \\
{[\mathrm{mm}]}\end{array}$ & $\begin{array}{l}\text { Reduction } \\
\text { at the } \\
\text { tunel roof } \\
{[\mathrm{mm}]}\end{array}$ \\
\hline $\begin{array}{l}\text { Model with } \\
\text { exploratory } \\
\text { gallery }\end{array}$ & 171 & 215 & 0 & 0 \\
\hline $\begin{array}{l}\text { Reinforcing } \\
\text { grouting }\end{array}$ & 159 & 193 & -12 & -22 \\
\hline $\begin{array}{l}\text { Anchoring } \\
\text { type } 1\end{array}$ & 97 & 125 & -74 & -90 \\
\hline $\begin{array}{l}\text { Anchoring } \\
\text { type } 2 *\end{array}$ & 154 & 197 & -17 & -18 \\
\hline $\begin{array}{l}\text { Micropiles } \\
\text { type } 1\end{array}$ & 123 & 150 & -48 & -65 \\
\hline $\begin{array}{l}\text { Micropiles } \\
\text { type } 2 *\end{array}$ & 152 & 190 & -19 & -25 \\
\hline Invert type 1 & 133 & 170 & -38 & -45 \\
\hline Invert type $2^{*}$ & 171 & 215 & 0 & 0 \\
\hline $\begin{array}{l}\text { Vertical } \\
\text { sectioning } \\
\text { type } 1\end{array}$ & 79 & 114 & -92 & -101 \\
\hline $\begin{array}{l}\text { Vertical } \\
\text { sectioning } \\
\text { type } 2^{*}\end{array}$ & 104 & 134 & -97 & -81 \\
\hline
\end{tabular}

* Time lag

the type used and the position of the exploratory gallery are not suitable for combining with vertical sequencing of the tunnel face.

\section{Conclusion}

The main goal of the research was to verify the application of suitable numerical models on the basic underground structures type. The whole course of comparison was computer simulated, using commercial PLAXIS software. An automatic generator was used for generating the finite element mesh. For the modelling we used quadratic triangular elements, which enable a sufficiently accurate analysis to be performed. Three tasks were prepared in order to study the behaviour of the numerical model:

Reduction of the tunneling effects on the Minorit monastery by means of a jet grouting curtain was modeled in the first task. The in-situ measured horizontal deformations of the protecting wall $(3 \mathrm{~mm})$ are of the same order as the deformations determined by FEM $(3.5 \mathrm{~mm})$. The levelling determined that the maximum value of the monastery foundation settlement is $5.9 \mathrm{~mm}$. This value is consistent with the settlement value determined by FEM modelling.

The behaviour of the Hvíždalka backfilled tunnel was modeled in the second task. The results determined by FEM 
modelling were compared with the in-situ measurements. This value is consistent with the settlement value determined by FEM modelling.

The numerical analysis of the supporting measures affecting on the tunnel deformations was performed in the last task. The aims of this project were:

- To create a reasonable static model of cross-section $\mathrm{km}$ 5.160, where the deformations were significantly high (about $80 \%$ higher values for the limit values than in the realization project).

- To evaluate the influence of supporting measures on decreasing the final deformations, and to analyse their suitability (i.e. addition of rock bolts, consolidation grouting and micropiling under top heading footings).

- To analyse possible causes of increases in of deformations above the originally supposed values (i.e., the specific properties of the studied cross-section, possible imperfections during construction).

- To evaluate other ways of reducing the tunnel deformations (alternative methods of sequencing the tunnel face vertical sequencing, closing the top heading by a temporary invert).

- To evaluate the influence of the excavation of a exploratory gallery on the static behaviour of the massif.

- After comparing of in situ measured deformation values with calculated deformations on the basic model, the effect of parametric changes on the final deformations was investigated. The middle values of the rock parameters were used for modelling purposes. The parameters of the tectonic fault vary slightly from the middle (due to more detailed investigation in profile $\mathrm{km} \mathrm{5.160).} \mathrm{The} \mathrm{results} \mathrm{of}$ the parametric study were examined to determine the roof arch settlement. The influence of cohesion and friction angle values on the results was also examined. factors:

The quality of the results was influenced by the following

- Reliable input data: The advantage of the Mrázovka project was the detailed site investigation. This enabled a relatively exact derivation of the rock massif characteristics in the examined cross section. The tectonic fault which affected the behaviour of the structure, was properly incorporated into the model thanks to co-operation with a geologist.

- NATM modelling: The option of single stage simulation during tunnel face excavation was used for this purpose. A description of the deformations made before the tunnel lining was added also had to be performed. It was created using the Beta method (the beta coefficient was chosen to be 0.67$)$.

- Monitoring during construction: The behaviour of profile $\mathrm{km}$ 5.160 was monitored in detail during construction. This enabled the model to be verifies by in-situ measured data.

\section{Acknowledgement}

This work was supported by Ministry of Education of the Czech Republic research project MSM210000003 "Developments of the Algorithms of Computational Mechanics and their Application in Engineering". This support is greatly acknowledged.

\section{References}

[1] Barták, J., Macháček, J., Pacovský, J.: Observation measuring of the earth-covered traffic tunnel structure in the quarry Hvíżalka. Tunel, No. 1/1998, pp. 6-9

[2] Barták, J., Hilar, M., Pruška, J.: Plaxis Program. Geotechnika, No. 2/2000, pp. 8-11

[3] Hudek, J.: The Mrazovka tunnels - measurement and monitoring at construction of the WTT-presiometric checking on the success of saving grouting - profiles 003 to 009. PÚDIS, Praha 1999

[4] Hudek, J., Chmelař, R., Verfel, J.: Additional engineering-geological investigation for the vehicular tunnel Mrázov$k a$-partial report - evaluation 2 of trial reinforcing grouting by Zakládáni staveb a.s. company at $\mathrm{km}$ 4.873-4.887. PÚDIS, Praha 1998

[5] Kolečkář, M., Zemánek I.: Monitoring of the Mrazovka tunnel. In: "Volume of papers of the Int. Conf. Underground Construction 2000", ITA/AITES, Praha 2000, pp. 427-433

[6] Mišove, P.: Check inclinometric measurements for securing stability of St. John's church in Brno. VUIS - Zakladanie stavieb, Bratislava 1996

[7] Salač, M.: Construction of the tunnel under Mrázovka Hill. Tunel, No. 4/1999, pp. 33-38

Prof. Ing. Jiří Barták, DrSc. e-mail: bartakj@fsv.cvut.cz

Dr. Ing. Jan Pruška

e-mail:pruska@fsv.cvut.cz

phone: +420224354548

fax.: +420224354556

Department of Geotechnics

CTU, Faculty of Civil Engineering

Thákurova 7

16629 Praha 6, Czech Republic

Ing. Matouš Hilar, M.SC.,Ph.D.

phone: +420241443411

D2 Consult Prague, s.r.o.

Na Usedlosti 513/16

14000 Praha 4, Czech Republic 